\title{
BMJ Open Meanings and senses of being a health professional with tuberculosis: an interpretative phenomenological study
}

\author{
Marcandra Nogueira Almeida Santos (D) ,, Antonia Margareth Moita Sá, ${ }^{1}$ \\ Juarez Antonio Simões Quaresma ${ }^{1,3,4}$
}

To cite: Santos MNA, Sá AMM, Quaresma JAS. Meanings and senses of being a health professional with tuberculosis: an interpretative phenomenological study. BMJ Open

2020;10:e035873. doi:10.1136/ bmjopen-2019-035873

- Prepublication history for this paper is available online. To view these files, please visit the journal online (http://dx.doi. org/10.1136/bmjopen-2019035873).

MNAS and JASQ are joint first authors.

Received 20 November 2019 Revised 27 June 2020 Accepted 02 July 2020

\section{Check for updates}

(C) Author(s) (or their employer(s)) 2020. Re-use permitted under CC BY-NC. No commercial re-use. See rights and permissions. Published by BMJ.

${ }^{1}$ Center for Biological and Health Sciences, University of Pará State, Belem, Para, Brazil ${ }^{2}$ Nursing Inspection Department, Regional Nursing Council, Belem, Para, Brazil

${ }^{3}$ Tropical Medicine Center, Federal University of Pará, Belem, Para, Brazil

${ }^{4}$ Pathology Research Section, Evandro Chagas Institute, Ananindeua, Para, Brazil

Correspondence to Dr Marcandra Nogueira Almeida Santos;

marcandraa@yahoo.com.br

\section{ABSTRACT}

Objective The aim of the study was to analyse and understand meanings and senses of living with tuberculosis for health professionals.

Method/design This is an interpretative phenomenological study conducted from in-depth interviews to analyse how health professionals understand their personal experience of tuberculosis.

Scenario Two reference health institutions for tuberculosis diagnosis and treatment located in a municipality of the Eastern Brazilian Amazon.

Participants Intentional sample of 15 health professionals with the disease or with a recent history of tuberculosis. Results Regarding the personal experience of tuberculosis of the participating health professionals, four superordinate themes were identified: (1) experiencing tuberculosis, (2) experiencing the diagnosis of tuberculosis, (3) facing the treatment of tuberculosis and (4) signifying tuberculosis.

Conclusion This study verified that health professionals live the experience of tuberculosis similar to other people: with fear, anguish, frustration, prejudice and health needs not always met by the services and programmes for the control of the disease. The lived experience has an important impact on the health professionals' ways of understanding the kind of empathic and sensitive care that should be provided to people with tuberculosis. In addition, it is concluded that specific governmental strategies are needed for tuberculosis prevention, diagnosis and treatment among health professionals.

\section{INTRODUCTION}

Tuberculosis (TB) is among the communicable diseases of greatest interest to world public health, as its identification and control persist as challenges to the health of the populations, especially in poor countries and with high levels of social inequality. The disease monitoring indicators show that the distribution of TB cases is worldwide, with a decreasing trend in mortality and morbidity rates in developed countries. ${ }^{1}$

Nevertheless, according to the WHO, about 10 million people are affected by TB each year, which makes the disease one of the top 10 causes of death on the planet and

\section{Strengths and limitations of this study}

- Using a qualitative approach, this study raised important questions about the care management for patients with tuberculosis, from the perspective of the health professional who also became a patient and lived the experience of diagnosis and treatment for the disease.

- The interviews analysed show similarities in the life experiences of the health professionals who fell ill with tuberculosis and, therefore, deserve further investigation.

- The findings of the study are limited to a small number of interviews and may not be representative of all the health professionals who fell ill with tuberculosis in the region.

the leading cause of death by a single infectious agent among people living with the HIV. $^{2}$

Brazil ranks 20th on the list of 30 priority countries for fighting TB in the world. ${ }^{2}$ The incidence of the disease in the country in 2018 was estimated at approximately 35 cases per 100000 inhabitants. The highest rates were registered in the states of Amazonas, Rio de Janeiro, Pernambuco, Acre, Roraima and Pará. In Pará, located in the Eastern Brazilian Amazon, the incidence of TB was estimated at approximately 41 cases per 100000 inhabitants. The state capital, Belém, registered 63 new cases per 100000 inhabitants. The TB mortality rate in Belém was the second highest among the Brazilian capitals (7 deaths per 100000 inhabitants). ${ }^{3}$

Among the most vulnerable groups for TB in Brazil and worldwide are the health professionals. These professionals work in the provision of health services as individual workers or as employees in health institutions and health programmes, whether or not subjected to public regulation. They should not be confused with the term human resources in health. ${ }^{4-8}$ 
According to the WHO, in 2016, 8144 TB cases were registered in health professionals in 60 countries. China accounted for $39 \%$ of these cases and Brazil for $13 \%$. TB notification rates among health workers in 54 of the 60 countries ranged from 0 to 701 cases/100 000 inhabitants, with the highest rate observed in Mozambique. Brazil was among the nations whose TB incidence rates in health professionals could not be estimated. ${ }^{1}$

In this context, it is necessary to know about the occurrence of TB in health professionals in Brazil; however, studies that focused on the subject are still incipient and, in their majority, portray quantitative research studies, which, although important, are not enough to understand the complexity of the experience of living with TB. ${ }^{9-12}$ This research represents the first qualitative study conducted in Brazil with health professionals who fell ill with TB. This study aimed to analyse and understand the meanings and senses of being a health professional with a personal experience in $\mathrm{TB}$ and its treatment.

\section{METHOD}

This is an interpretative phenomenological study based on the theoretical framework of philosopher Martin Heidegger. ${ }^{13}$ This type of study allows analysing in detail and case by case how different people reflect and signify a certain similar experience in their lives. It is constantly used in health research studies because it is an ideographic approach that allows for a rigorous exploration of how diseases and healthcare impact on the individuals' experiences. ${ }^{14-16}$

The study took place in two reference institutions for the diagnosis and treatment of TB belonging to the public health network of Belém, Pará, in the Eastern Brazilian Amazon. Fifteen health professionals participated in the research, whose profiles were as follows: six nurses, six nursing technicians, two physicians and one laboratory technician; 14 female professionals, between 38 and 59 years old. Three professionals reported home contact with TB and one reported drug-resistant TB. No participating professionals withdrew from the study.

To access the participants, 10 meetings were held in order to disseminate the research in the reference institutions, in April and May 2017, with information presented by the lead researcher to any health professional who accepted it, regardless of their TB history. At the meetings, the professionals were informed about the study and encouraged to participate voluntarily if they met the inclusion criteria. Telephone contacts and email addresses of the lead researcher were made available to all meeting participants.

For those who voluntarily agreed to participate in the study, individual and face-to-face interviews were scheduled at dates and places chosen by the participants, according to their convenience. The interviews took place mainly in the participants' homes and in the meeting rooms of the two health institutions, according to the participants' request.
The interviews were held in May and June 2017, lasted from 20 to $65 \mathrm{~min}$ and were guided by a script containing the following questions: How was your experience with TB? How was living the diagnosis and treatment of TB? How do you signify TB?

The meetings and interviews were closed when data saturation was reached and no other topics emerged in our analysis. A lead female researcher, trained in qualitative methods and with no prior relationship with the participants, conducted the interviews, which were digitally recorded, transcribed and made anonymous immediately after each meeting.

The transcribed interviews were analysed in detail by MNAS and AMMS. To balance the analysis and to strengthen the reliability of the interpretations, the researchers read the material more than once to familiarise themselves with the participants' statements. Subsequently, they then made general and specific annotations in each of the transcripts to document exploratory coding, identify the emerging themes, the convergences and divergences, and compare their annotations with each other, with the aim of reaching consensus of opinion and enabling a more rigorous interpretative understanding of the speeches.

In the first analysis of the interviews, four units of thematic significance were organised, which portray what the health professionals think and speak about their own, a prereflexive understanding that occurs in the daily life of the experienced facts. ${ }^{16}$ Then, through an interpretative analysis based on Heidegger's phenomenology, the meanings of being a health professional with TB were unveiled. ${ }^{17-20}$

For this analysis, the main Heidegger's concepts presented in his work 'Being and Time' were considered. According to the philosopher, the human sense of being is often hidden by apparent meanings, which need to be unveiled as possible ways of being and living in the world. $^{21}$

Thinking human beings on the basis of the relationship with their own beings, Heidegger used the expression 'dasein (there-being)' to designate not only the very existence of each human being but also a privileged way of being. Heidegger presents 'dasein (there-being)' as an underlying principle of human ontology, since we are sentient beings, we have an embodied understanding of our sense of self, we can evolve learning, learn more from each other. From this perspective, hermeneutic analysis allows us to overcome any preunderstanding we have of the world through a careful analysis of human experience, insofar as understanding the essential qualities of an experience can illuminate that experience for others. ${ }^{22}$

In this study, the interpretative analysis of the speeches was based on the phenomenological description of the ways of being among the participating health professionals. Heidegger named this movement of analysis 'a hermeneutic circle', which is composed of preunderstanding, understanding and interpretation..$^{23}{ }^{24}$ In this way, to understand the experience of the participants, we 
carry out a 'project' in relation to the meaning of the individual parts and the whole of the interviews, in the same way that we start from our previous conceptions, that are culturally, socially and environmentally constructed, to carry out the interpretation. In a circular motion, we interrogate the data, reflect and revise our preunderstandings, perform interpretations and reach new understandings. This comprehensive movement considers that the researchers are understanding the participants and the participants are understanding their experience. ${ }^{25}$

All the phases of this study were carried out in accordance with the ethical standards in research with human beings. In addition, informed consent forms were obtained from all the participants. We used the Standards for Reporting Qualitative Research (SRQR) checklist when writing our report. ${ }^{26}$

\section{Patient and public involvement}

No patients involved.

\section{FINDINGS}

\section{Experiencing TB}

According to most of the statements, at the beginning of the clinical condition, and for some time, TB remains imperceptible to the sick health professional because at this stage the symptoms are scarce and may be confused with other diseases. In the everyday life of these professionals, the initial signs and symptoms of TB were ignored or tolerated, always to the detriment of the need to fulfil an intense routine of daily tasks and occupations. In some cases, the health professionals even realise that there is something wrong, but they choose self-medication as a strategy to minimise the clinical condition, so that they do not become patients.

I thought it was a common cold... it never crossed my mind that I had tuberculosis. (Interviewee No. 4)

I did feel some respiratory discomfort, but I'm asthmatic, so I believed it was because of asthma... I didn't associate it with tuberculosis. (Interviewee No. 14)

The initial non-identification of the disease is almost always due to the prevalence of non-specific signs and symptoms. But the chores of daily life and the excessive rush in which they stay most of the time lead to selfmedication as a strategy to minimise the clinical condition and to make it feasible to comply with the routine of activities and occupations.

I had really characteristic symptoms like afternoon fever, chest pain, weight loss... but health professionals have a habit of self-medication... I self-medicated because life can't stop! (Interviewee No. 9)

However, over time, ТВ becomes more and more apparent, as signs and symptoms are more frequent, uncomfortable and worrying, leading sick health professionals to reflect on the need to be aware of their own health. When more severe signs of pulmonary TB are presented, for example, they realise their condition of clinical severity and, after recognising the possibility of a positive TB diagnosis, understand it as something disturbing.

It was fever every late afternoon, you know? A month later came hemoptysis. So it was terrible! Because when I saw that blood in the sink I said: 'My God in Heaven, it's not possible!' And I tasted the blood ... when I spat I said: 'it's TB!' (Interviewee No. 5)

\section{Experiencing the TB diagnosis}

TB diagnosis was sought at the very workplace almost always, as it offers the human resources and technologies needed to investigate the disease. In addition, the concern and daily support from colleagues allow the sick health professional to have faster access to clinical evaluations and to carry out the complementary diagnostic examinations.

However, when receiving a positive TB diagnosis, the healthcare professional gets shocked, surprised, tearful, nervous, frustrated and even desperate. Many live the moment with sadness and non-conformity, as they did not consider TB a real possibility for their lives. In this perspective, TB diagnosis represents to health professionals the loss of their identity and of the set of characteristics that have previously distinguished them from their patients.

I was very shocked and I cried a lot that day ... I was very anxious and very nervous. (Interviewee No. 2)

When I received the news the first thing I thought was that at some point I was careless ... it was disappointing! It was frustrating! (Interviewee No. 6)

Sometimes, distressed and desperate, the health professional looks for reasons to understand and explain the disease and does not always accept the TB diagnosis. Many fear death or worry about not transmitting the disease to their families and friends, so they choose to isolate themselves as a protective measure for others.

I then isolated myself in a small room ... I used to say: 'let me stay here quietly, at least I don't bother anyone.' (Interviewee No. 4)

I said: 'Oh, my God! If my mother gets this disease, I'm guilty!' I got scared, I thought and wondered: 'am I going to die?' (Interviewee No. 15)

A positive TB diagnosis makes the sick health professional live as a patient and, for many of them, this means feeling limited and depressed. Some remember unsuccessful work environment experiences and may interfere negatively in their own treatment.

I was supposed to take an exam, but I left! I was afraid to put a drain because I saw a patient die with pneumothorax and I was afraid ... I left! I left the hospital! $\ldots$ at that moment I was no longer the caregiver, the 
professional, I became the patient so I became depressed. (Interviewee No. 13)

\section{Facing the treatment of TB}

After experiencing the first impact of TB diagnosis, some health professionals reflect on the epidemiology of the disease and on the negative consequences of not adequately taking the necessary drugs. They believe that attitudes of persistence and self-care should prevail over fear and over the occasional willingness to abandon the treatment.

I knew the epidemiology of the disease, I knew that if it was treated soon, it would have a greater chance of cure, so I tried to do everything right. (Interviewee No. 1)

I managed to get the treatment, but it's cruel every day (referring to the anguish of taking drugs for the treatment of TB), there were days when I said: 'ah! I can't take it!' Because we do (the treatment), but you have to be very conscious and persistent. (Interviewee No. 11)

During the treatment, two professionals decided to refuse a specific therapeutic procedure (chest drainage) due to fear of unsuccessful events that could lead to death, recalling past professional experiences with other patients who underwent unsuccessful chest drainages.

The treatment directly observed in health units was indicated for all health professionals; however, it was understood as a problem for some respondents, as they needed to face queues, sometimes for hours, waiting to be assisted. They felt wronged and requested the selfadministered drug treatment because, in their understanding, as they were health professionals they had a lower risk of abandoning treatment and needed differentiated care.

In this perspective, some professionals showed a limited and ambiguous understanding on the need of a directly observed treatment because they were experiencing a battle between being ill and being a health professional; thus, they did not recognise the importance of adopting this strategy to qualify their own care. Moreover, supervised treatment is not limited to preventing discontinuation of the anti-TB medications; it also seeks to strengthen the bonds between patients and health services with the aim of attaining health and disease control goals for all population groups in different regions of the country.

I agree, I accept that (the treatment) has to be supervised, because it is supervised, but I felt like some irresponsible people who abandoned treatment, you know? It wasn't my case... so why didn't they give the drugs to me? [referring to the medications not delivered for self-administered treatment]. 'I'm a health professional, guys! I want to treat myself!' (Interviewee No. 15)
Another moment of conflict for some respondents was the return to the work routines because they understand that the mean period of 15 days of sick leave granted by the occupational health services of the institutions where they work is insufficient. They understand that not only physical recovery is important but also psychic and mental health.

The doctor advised me that from 15 days on taking the pill I'd no longer transmit TB to anyone... but I wasn't fine yet and remained at home [referring to the refusal to return to work after 15 days of absence]. (Interviewee No. 10)

I think the hospital has to support the employee's mental health and to know what it's like for everyone... I was going to that hospital, but only God knows how I was going to work! (Interviewee No. 15)

\section{Signifying TB}

Experiencing the disease has led some professionals to understand that TB is inevitable because they are health professionals and are at greater risk. Nevertheless, they recognise the need and importance of specific care to prevent further TB cases.

When it has to happen, it really happens... it's no use preventing, hiding. (Interviewee No. 4)

For me, TB is a disease that any of us can get because it's transmitted by droplets in the air. (Interviewee No. 10)

Nowadays I use the most reinforced mask more than ever! (Interviewee No. 12)

I believe we have to be more careful about our work environment, we have to protect ourselves, take better care of ourselves. (Interviewee No. 7)

Many health professionals decided to disclose their TB disease status to distant relatives, but they experienced judgement and prejudice, which intensified their suffering and their desire to remain isolated in their homes. Another negative consequence resulting from TB was a reduced working capacity, which can cause sadness and significant financial losses.

One thing that struck me a lot was prejudice... no matter how much I said: 'there's no risk of transmission!' But nobody believed... I tried to understand, but it's hard for you to feel that way, discriminated in some way. (Interviewee No. 2)

If there's one thing that made me sad because of tuberculosis was losing Medicine... Medicine as I liked to do... my body can't take the shifts anymore [referring to the previous 12 hours workday in an intensive care unit]. (Interviewee No. 6)

I had to give up a job, my debts multiplied, my salary went down... there were several consequences due to tuberculosis. (Interviewee No. 13) 
On the contrary, experiencing the disease allowed for changes in understanding and behaviour and encouraged the current strengthening of bonds among the majority of the health professionals interviewed and their patients.

Nowadays I try to reinforce more (talk more to the patient): 'look, don't abandon, you haven't healed yet!' (Interviewee No. 2)

Tuberculosis has changed my point of view... what I'm trying to do now is to guide so that it's not transmitted. (Interviewee No. 3)

Nowadays, when I meet a patient who is diagnosed with tuberculosis, I tell him/her: 'don't give up! Look at me! I had tuberculosis and I'm here, you can do it too!' Patients get impressed... they feel safer, more understood. (Interviewee No. 14)

\section{DISCUSSION}

According to Martin Heidegger, authentic understanding of the human phenomena must be sought and achieved through phenomenological interpretation. In the philosopher's proposal of theory and method, the circular understanding movements (the comprehension, interpretation and new comprehension triad) were described, which allow revealing meanings and senses of being and understanding the world and oneself. ${ }^{27-30}$

The disease caused by TB gradually changed the daily life experienced by all the health professionals interviewed. According to Heidegger, is in daily life that the being-there lives and coexists as a being-in-the-world, and from which it exists and articulates diverse other ways of being. ${ }^{13}$ It is not a way of being lost, flawed or degraded. On the contrary, it is the way of being that constitutes us and ontologically allows us all the possibilities of being. ${ }^{30-32}$

On being diagnosed with the disease, the health professional beings with TB may be shocked, sad, disappointed, defeated and even guilty and seek reasons to understand how and why they fell ill. For Heidegger, this understanding reveals itself as a way of existing of the beingthere, because it is understanding that they see themselves as beings of possibilities. In any case, understanding can take place in proper or inappropriate, authentic or inauthentic ways of being. ${ }^{33} 34$

In a way of being inauthentic, the health professional beings with TB live in everyday life the phenomenon called ambiguity because, if on one hand they say they recognise the disease, on the other hand, by being shocked and surprised with the diagnosis, they act as if not understanding the modes of transmission and the risks of TB determined by their own professional conditions. Even when suspicious, they prefer not to recognise the initial symptoms of $\mathrm{TB}$, because they want to refute any concrete possibility of the disease.

In certain cases, the health professional beings with TB say they agree and accept that the treatment regimen be supervised, but their understanding is ambiguous as they accept and agree to supervised treatment for others and not for themselves. They understand that being healthcare professionals makes them different, more responsible and more willing to comply with the medication scheme from start to finish without abandoning it.

It is in the face of the phenomenon of ambiguity that everything seems to be understood, discussed and interpreted in an authentic way for us, when in fact it was not; at other times, authentic understanding does not seem to have happened, but it has in fact occurred. The phenomenon of ambiguity extends to the relations of being-inthe-world, of being-with others and of being-oneself of the being-there. ${ }^{13}$

For the health professional beings with $\mathrm{TB}$, the disease represents in everyday life the ontic possibility of death and, therefore, they fear it. This fear is also revealed from memories of unsuccessful work experiences lived during the care of others with TB.

Under such circumstances, guided by the fear of death and in order to escape from it, the health professionals with TB may refuse a specific care or therapeutic procedure that may be directed at them, thereby negatively interfering with the recovery of health. When feeling threatened by the possibility of death, what is at stake for the health professional beings with TB is the being-with and being-together with other beings in the world; they fear the possibility of no longer existing, as physical death would represent the finitude of their occupations and concerns. Heidegger believed that it is still in the course of existence that the being-there actually dies, when it does not recognise its own being-toward-death and runs away from itself, ceasing to relate to it as a may-be. ${ }^{29-34}$

In turn, when concerned about not transmitting TB, health professionals seek to isolate themselves from living with other people but, from an ontological point of view, the intended isolation will never constitute a factual possibility, since in the world we are always being-with, to the extent that to exist is always to coexist and to live is always to live with. ${ }^{13}$ By expressing concern not to transmit the disease, the health professional beings with TB seek to escape the guilt that would feel if those who are close also fell ill.

These health professional beings with TB experience in their daily life the phenomenon called chatter, which translates into listening, repeating or passing on the speech (oral or written) without having a commitment of original appropriation with the content of this speech. ${ }^{32}$ It is because of the chatter that prejudice against TB is sustained, because the danger posed by the disease allows us to understand and interpret many things in a medium way. However, it is important to point out that average understanding and interpretation can never be taken away from our existence, for it is in them, from them and against them that every possibility of authentic understanding and interpretation moves. ${ }^{33} 35$

After becoming ill and living the TB treatment, the health professionals allow themselves to redefine care, as they understand that the experience with the disease 
brought them more sensitivity to understand the difficulties that other patients face, and this encourages them to promote positive changes in their care attitudes and practices.

Even for a moment, health professional beings with TB may understand the disease only as one of their possibilities in the world, from which they cannot escape. When decided for treatment and free from improper anguish (or fear), they can reveal their most proper and authentic way of being-oneself.

For Heidegger, being-oneself means a movement to one's own being, a passage of the impersonal that occurs through a choice, a decision. ${ }^{13} 36$ This is when the beingthere becomes free to choose oneself, opening as a possible-being and breaking with the everyday familiarity in which it remains most of the time, even for a moment.

The findings of this study are limited to a small number of interviews and may not be representative of all the health professionals who fell ill with TB in the region. Additionally, the findings may be related to a specific moment, and any change in the life context of the health professionals or in time may lead to changes in the data and in the findings. Despite this, the qualitative design of the study enabled a thorough understanding of the phenomenon, and the analysed speeches reveal important similarities in the life experiences of the professionals. From this perspective, the findings obtained in this research may be useful to create medical care and support strategies for the health professionals who fell ill to cope with TB. These professionals provided us with important information on the experience of becoming TB patients, but we do not know which factors involved in their health conditions influenced their perceptions and feelings toward $\mathrm{TB}$, a topic worth exploring in future research studies.

\section{CONCLUSION}

The results of this study revealed important issues for TB control in health professionals in the Eastern Brazilian Amazon, as they indicate that these professionals can live the experience of illness with anguish, fear, guilt, frustration, prejudice and health needs not always met by disease control programmes. Nevertheless, the experiences lived by the interviewees encouraged them to reflect on the complexity of TB and on the importance of individualised, humanised and sensitive care for all people facing the disease, which may help them in their care relationships with their patients. It is suggested that government strategies for TB control in health professionals are needed in the studied region. These strategies need to go beyond the specific actions and the occupational health programmes in the large institutions.

Acknowledgements The authors are grateful to the health professionals participating in the study, for freely giving their support and time, and Dr Marília de Fátima Vieira de Oliveira, Dr Laura Maria Vidal Nogueira and Dr Nelson Veiga Gonçalves for their support. The authors thank the Program of support for qualified Production of the Federal University of Pará - PAPQ/PROPESP/UFPA.
Contributors MNAS, JASQ and AMMS contributed to the conception and design of the study. MNAS was responsible for data collection and transcription. MNAS and AMMS were responsible for data analysis and interpretation. MNAS, JASQ and AMMS were responsible for writing and reviewing the manuscript critically and for approving the final version of the article for publication.

Funding This work was supported by the Fundação Amazônia Paraense de Amparo à Pesquisa (Fapespa), Brazil, through Public Notice No 0052016.

Competing interests None declared.

Patient consent for publication Not required.

Ethics approval This study was approved by the Human Research Ethics Committee of the State University of Pará, Brazil, under number 2,019,968/2017.

Provenance and peer review Not commissioned; externally peer reviewed.

Data availability statement No additional data are available.

Open access This is an open access article distributed in accordance with the Creative Commons Attribution Non Commercial (CC BY-NC 4.0) license, which permits others to distribute, remix, adapt, build upon this work non-commercially, and license their derivative works on different terms, provided the original work is properly cited, appropriate credit is given, any changes made indicated, and the use is non-commercial. See: http://creativecommons.org/licenses/by-nc/4.0/.

ORCID iD

Marcandra Nogueira Almeida Santos http://orcid.org/0000-0002-0017-855X

\section{REFERENCES}

1 World Health Organization. Global tuberculosis report, 2017. Available: http://www.who.int/tb/publications/global_report/en/ [Accessed 29 Sep 2018].

2 World Health Organization. Global tuberculosis report, 2019. Available: http://www.who.int/tb/publications/global_report/en/ [Accessed 11 Nov 2019].

3 Ministério da Saúde. Brasil Livre dA Tuberculose: evolução DOS cenários epidemiológicos $\mathrm{E}$ operacionais dA doença. Boletim Epidemiológico 2019;50:1-18.

4 Organização Pan-Americana da Saúde. Centro Latino-Americano E do Caribe de Informação em Ciências dA Saúde. Descritores em Ciencias dA Saúde, 2019. Available: http://decs.bvs.br [Accessed 10 Jul 2019].

5 Hosoglu S, Tanrikulu AC, Dagli C, et al. Tuberculosis among health care workers in a short working period. Am J Infect Control 2005;33:23-6.

6 Dimitrova B, Hutchings A, Atun R, et al. Increased risk of tuberculosis among health care workers in Samara Oblast, Russia: analysis of notification data. Int J Tuberc Lung Dis 2005;9:43-8.

7 Pai M, Kalantri S, Aggarwal AN, et al. Nosocomial tuberculosis in India. Emerg Infect Dis 2006;12:1311-8.

8 Saleiro A, Santos R, Vidal O, et al. Tuberculosis in healthcare professionals in a hospital service. Rev Port Pneumol 2007;13:789-79.

9 Prado TN, Galavote HS, Brioshi AP, et al. Epidemiological profile of notified cases of tuberculosis among health professionals at the university hospital in Vitória (ES) Brazil. J Bras Pneumol 2008;34:607-13.

10 Prado TNdo, Riley LW, Sanchez M, et al. Prevalence and risk factors for latent tuberculosis infection among primary health care workers in Brazil. Cad Saude Publica 2017;33:e00154916.

11 Bavaresco ACW, Busatto C, Reis AJ, et al. Latent tuberculosis among professionals from a referral hospital in oncology. Clin. Biomed. Res. 2017;37:281-7.

12 Paula DG, Coelho TC, Motta MMS, et al. Occupational tuberculosis: documentary analysis of a university hospital in Rio de Janeiro.. Rev Cubana Enferm 2015;31.

13 Heidegger M. Being and time. Petrópolis, RJ: Vozes Publishing Company, 2015.

14 Norton W, Furber L. An exploration of how women in the UK perceive the provision of care received in an early pregnancy assessment unit: an interpretive phenomenological analysis. BMJ Open 2018;8:e023579.

15 Meaney S, Corcoran P, Spillane N, et al. Experience of miscarriage: an interpretative phenomenological analysis. BMJ Open 2017;7::e011382.

16 Astolphi SM, Palacio FCL, Lione ML. Nursing research supported by the phenomenological framework of Martin Heidegger. Avances em Enfermería 2018;36:230-7. 
17 Sebold LF, Locks MOH, Hammerschmidt KSA, et al. Heideggerian Hermeneutic circle: a possibility of interpretation of nursing care. Texto \& Contexto-Enfermagem2017;26:e2830017.

18 Guerrero-Castañeda RF, Menezes TMdeO, Prado MLdo. Phenomenology in nursing research: reflection based on Heidegger's hermeneutics. Escola Anna Nery 2019;23:e20190059.

19 Stein H. Six studies on being and time. Petrópolis, RJ: Vozes Publishing Company, 2014.

20 Almeida FS. Sentido E novidade das noções de fenomenologia E de hermenêutica no pensamento de Heidegger. Pensar-revista eletronica da FAJE 2014;5:197-207.

21 Piolli KC, Decesaro MdasN, Sales CA. (not) taking care of yourself as a woman while being a caregiver of a partner with cancer. Rev Gaucha Enferm 2018;39:e2016-69.

22 Gadamer HG. Truth and method: fundamental traits of a philosophical hermeneutics. Petrópolis, RJ: Vozes Publishing Company, 2015.

23 Sebold LF, Kempfer SS, Girondi JBR, et al. Perception of nursing faculty on the care: Heidegger constructions. Rev Esc Enferm USP 2016;50 Spec:39-46.

24 Santos MNdeA, Sá AMM. Living with tuberculosis in prison: the challenge to achieve cure. Texto contexto - enferm. 2014;23:854-61.

25 Smith JA, Flowers P, Larkin M. Interpretative phenomenological analysis: theory, method and research. Los Angeles: Sage Publications Inc, 2009
26 O'Brien BC, Harris IB, Beckman TJ, et al. Standards for reporting qualitative research: a synthesis of recommendations. Acad Med 2014;89:1245-51.

27 Schmidt LK. Hermeneutics. Petrópolis, RJ: Vozes Publishing Company, 2014

28 Stefani J, Cruz NOda. Compreensão E linguagem em Heidegger: exsistência, abertura ontológica E hermenêutica. Bakhtiniana: Revista de Estudos do Discurso 2019;14:112-27.

29 Cardinalli IE. Heidegger: the study of human phenomena based on human existence as being-there (Being-there). Psicologia USP 2015;26:249-58.

30 Heidegger M. Ontologia hermenêutica da facticidade. Petrópolis, RJ: Vozes Publishing Company, 2013.

31 Johnson Muñoz FA, Muñoz FJ. Dasein Y auto-apropiación. El tiempo como constitutivo de nuestra realidad Co-herencia 2018;15:93-120.

32 Salimena AMO, Elias EA, Souza IEO, et al. Gossip and occupation in daily life of nursing professionals in itself and the other care. Revista Baiana de Enfermagem 2016;30:316-24.

33 Cerbone DR. Phenomenology. Petrópolis, RJ: Vozes Publishing Company, 2014.

34 Braga TBM, Farinha MG. Heidegger: em busca de sentido para a existência humana. Revista abordagem Gestalt 2017;23:65-73.

35 Kirchner R. A analítica existencial heideggeriana: Um modo original de compreender O Ser humano. Revista do NUFEN 2016;8:112-28.

36 Chillón JM. Los rendimientos fenomenológicos de la angustia en Heidegger. Alpha 2018;46:215-32. 